$\begin{array}{lll}\text { Bentham open } & \text { The Open Anesthesia Journal } \\ \text { CrossMark } & \text { Content list available at: www.benthamopen.com/TOATJ/ } \\ \text { DOI: } 10.2174 / 2589645801812010094,2018,12,94-100 & \end{array}$

CLINICAL TRIAL STUDY

Efficacy and Safety of Magnesium versus Dexmedetomidine as Additives to Local Anesthetic Mixture Using Single Injection Percutaneous Peribulbar Anesthesia in Vitreoretinal Surgeries

\author{
Aktham Shoukry ${ }^{*}$ and Amr Sobhy Abd el Kawy \\ Anaesthesia \& ICU, Ain Shams University, Cairo, Egypt
}

Received: September 25, 2018

Revised: October 26, 2018

Accepted: November 12, 2018

\begin{abstract}
:
Background:

Peribulbar block for vitreoretinal surgery is rather associated with delayed onset of globe anesthesia, akinesia and short duration of analgesia.
\end{abstract}

\title{
Objective:
}

To compare the effect of addition of Magnesium sulphate $v s$ dexmedetomidine to standard local anesthetics mixtures on the time of onset of Globe Anesthesia, Akinesia \& analgesia duration.

\section{Patients and Methods:}

Ninety patients of both sexes, aged 25- 75 years, ASA I-III scheduled for vitreoretinal surgery. They were randomly allocated into 3 equal groups each received peribulbar block a mixture of Levo- bupivacaine $0.5 \%(3 \mathrm{ml})+$ lidocaine $2 \%(3 \mathrm{ml})+120 \mathrm{IU}$ hyaluronidase + Control group (C): $0.5 \mathrm{ml}$ of Normal saline. Group (M): $50 \mathrm{mg}$ of Magnesium sulphate in $0.5 \mathrm{ml}$ normal saline. Group (D): $50 \mu \mathrm{ic}$ of dexmedetomidine in $0.5 \mathrm{ml}$ normal saline. The duration of sensory, motor block, Sedation level, Intra-ocular Pressure (IOP) and surgeon satisfaction were assessed.

\section{Results:}

The onset of globe anesthesia and akinesia was significantly shorter in M group in comparison with D and C Groups, with a significant increase in the duration of globe analgesia and akinesia in the D Group when compared to both M \& C groups. Groups D and $\mathrm{M}$ showed a statistically significant decrease in the IOP at $5 \mathrm{~min}$ and $10 \mathrm{~min}$ when compared to the baseline measurement of the same groups \& to C Group, no complications or adverse effects related to the drug or technique were recorded.

\section{Conclusion:}

Magnesium sulphate as a local anesthetic adjuvant in peribulbar block is safe and comparable to dexmedetomidine regarding the sensory and motor block duration with better cost-effectiveness and availability.

Keyword: Magnesium sulphate, Dexmedetomidine, Peribulbar block, Single injection, Local anesthetic adjuvant, Vitreoretinal surgeries.

\section{INTRODUCTION}

Vitreoretinal surgeries are one of the commonest operation performed across the world, they are deemed to be long and uncomfortable for patients to tolerate. The vast majority of these procedures can be safe, comfortable, efficient and

\footnotetext{
* Address correspondence to this author at Anaesthesia \& ICU, Ain Shams University, Cairo, Egypt; Tel: 01009506027; E-mail: aktham.shoukry1@gmail.com
} 
performed under properly monitored local anesthesia. Local analgesic adjuvants are used to enhance the nature of local anesthesia for enhancement of akinesia onset, prolong the duration and decrease the postoperative pain, added substances like hyaluronidase, adrenaline, clonidine; sodium bicarbonate, corticosteroids and neuromuscular blocking drugs have been utilized as a part of peribulbar block with a limited rate of success [1 - 6].

Magnesium sulfate has been utilized for a long time with local anesthetic solutions in various techniques of regional anesthesia to decrease the onset time of the blockade and to enhance the quality and duration of anesthesia; such impacts are basically based on physiological calcium opposition and noncompetitive antagonist of N-methyl-DAspartate (NMDA) receptors [7] dexmedetomidine is centrally acting highly specific $\alpha 2$-agonist commonly used as sedative, preemptive analgesic and proved to decrease the onset of anesthesia and increase the duration of analgesia and akinesia in neuroaxial and regional blocks [8]. Both of them were tested in different concentrations as adjuvant to peribulbar anesthesia and their benefits regarding the quality of the block were tested in several studies [9, 10].

In order to find best local anesthetic adjuvant with least complication and best cost-benefit with simple technique, we compared the effect of addition of Magnesium sulphate $v s$ dexmedetomidine to standard local Anesthetics mixtures on the time of onset of Globe Anesthesia, Akinesia and their duration with pain relief to suit the relatively long vitreoretinal surgeries producing optimal operating conditions.

\section{MATERIALS AND METHODS:}

This prospective randomized, double-blind, and controlled study was conducted on 90 patients ASA I - III, age ranged between 25 and 75 years and scheduled for elective vitreoretinal surgery under local peribulbar anesthesia. Participants were enrolled from March 2016 to December 2017 at Ain Shams University Hospitals. Patient informed written consent and Local Ethical Committee approval have been obtained before patient's allocation.

Exclusion criteria included age younger than 18 years, coagulopathy, communication problems, or allergy to any of the study medications. Furthermore, patients were excluded if they had the severe cardiac disease, chronic obstructive lung disease, and a history of sleep apnea.

These patients were randomly allocated using closed envelopes into 3 equal groups (n 30):

Control Group (Group C): Received mixture of Levo-bupivacaine

$0.5 \%(3 \mathrm{ml})+$ lidocaine $2 \%(3 \mathrm{ml})+120 \mathrm{IU}$ hyaluronidase $+0.5 \mathrm{ml}$ of Normal saline.

Magnesium sulphate Group (M): Received mixture of Levo-bupivacaine

$0.5 \%(3 \mathrm{ml})+$ lidocaine $2 \%(3 \mathrm{ml})+120 \mathrm{IU}$ hyaluronidase $+50 \mathrm{mg}$ of Magnesium sulphate $(50 \mathrm{mg}$ in $0.5-\mathrm{ml}$ saline $)$.

Dexmedetomidine Group (D): Received mixture of Levo-bupivacaine

$0.5 \%(3 \mathrm{ml})+$ lidocaine $2 \%(3 \mathrm{ml})+120 \mathrm{IU}$ hyaluronidase $+50 \mu \mathrm{g}$ of dexmedetomidine (50 mic in 0.5 - $\mathrm{ml}$ saline) .

All patients received single-injection percutaneous peribulbar block by an experienced anesthesiologist, and both the patient and the anesthesiologist were blinded to the drug mixture used.

Patients arrived in the operating room unpremedicated and having fasted for the preceding 8 hours. A peripheral IV cannula was inserted; and standard monitoring, including Noninvasive Arterial Blood Pressure (NIBP), electrocardiogram (5 leads), Heart Rate (HR) and peripheral oxygen saturation $\left(\mathrm{SpO}_{2}\right)$ were used.

The injection site was percutaneous and limited superiorly by the inferior lacrimal canaliculus, medially by the lateral margin of the nose, laterally by imaginary perpendicular line joining inferior lacrimal papilla to the inferior margin of the orbit and inferiorly by the inferior margin of the orbit. The needle was advanced in an anteroposterior direction for half of its length and then obliquely in the direction of the optical foramen, as described by Rizzo et al. [11].

The needle used was a 25-gauge, 16-mm, short-bevel needle. After negative aspiration, $6.5 \mathrm{~mL}$ of the local anesthetic solution was slowly injected.

Gentle ocular massage was applied intermittently to eyeball to promote the local anesthetic spread at the same time IOP was measured using indentation tonometry before injection and 1, 5, 10 minutes after injection.

Corneal sensation was evaluated using cotton wick every 30 seconds till the onset of anesthesia and every 30 minutes till recovery. 
The degree of globe and lid akinesia was evaluated in the 4 quadrants using a 3 point scoring system described by Sarvela: $(0=$ complete akinesia, $1=$ partial akinesia, 2 = normal movements $)$ the time for complete akinesia $(0)$ was recorded in all patients. The presence of ocular anesthesia together with globe $\&$ lid akinesia score $\leq 1$ was considered satisfactory to start the surgery. If inadequate motor block is observed 10 minutes after block, supplementary anesthesia of $3 \mathrm{ml}$ of lidocaine $2 \%$ was injected into the involved quadrant.

Supplemental $\mathrm{O}_{2}$ at $2 \mathrm{~L} / \mathrm{min}$ via nasal cannula was used throughout the procedure.

The following measures were assessed:

1. The duration of sensory and motor block: by the onset of pain and recovery of the eyeball movement respectively. Using a 5 point Verbal Rating Scale (VRS) recorded intra operatively every 30 min and postoperatively every $2 \mathrm{~h}$ for $6 \mathrm{~h}$ after the operation $(0=$ no pain, $1=$ mild pain, $2=$ moderate pain, $3=$ severe pain and $4=$ unbearable pain). If VRS score $\geq 2$ was reported intraoperatively additional supplementary local anesthesia subtenon's block was administered while postoperatively ketolorac $30 \mathrm{mg}$ intramuscular is given.

2. Sedation levels: with modified Ramsay sedation scale: (1- Anxious and agitated, 2- cooperative, tranquil, 3responds to commands, 4- brisk response to light tap or loud) $15 \mathrm{~min}$ during surgery and every $30 \mathrm{~min}$ during first 2 hours postoperatively.

3. Intra-ocular Pressure (IOP): Before injection of LA (baseline) and after a complete akinesia of the globe before surgical incision.

4. Patients' hemodynamics: Heart Rate (HR) and mean arterial blood pressure (MAP) recorded every 5 min during the surgery and in the immediate postoperative period (at 15 and $30 \mathrm{~min}$ ).

5. Adverse effects or complications related to the technique and the drugs used e.g. bradycardia (if heart rate decrease less than $50 \mathrm{~b} / \mathrm{m}$ ), hypotension (if decrease 30\% in baseline mean BP), globe perforation, hemorrhage are recorded and managed if present (bradycardia will be treated by atropine $0.5 \mathrm{mg}$ to be repeated if no response till $3 \mathrm{mg}$, increment dose of ephedrine in case of hypotension as it usually temporally effect.

6. Surgeon satisfaction: at the end of the surgery using a simple verbal scale $(1=$ satisfied, $0=$ unsatisfied).

\subsection{Statistical Methods}

With respect to sample size calculation, it was calculated using PS (version 3.0.43, Department of Biostatistics, Vanderbilt University, located in Nashville, United States). Based upon the assumption that adding Dexmedetomidine or magnesium to local anesthetic prolongs the duration of sensory block by $20 \%$ and taking power 0.8 and alpha error 0.05, a minimum sample size of 30 patients was calculated for each group.

The decrease in the time of onset anesthesia and prolonging the duration of the block when either Magnesium sulphate or Dexmedetomidine added to Levo-bupivacaine/hyaluronidase mixture for percutaneous peribulbar is considered as the primary endpoint of this study.

Statistical analysis was performed using computer software statistical package for the social science (SPSS, version 20; SPSS Inc., Chicago, Illinois, USA). Description of quantitative (numerical) variables was performed in the form of mean \pm SD. Description of qualitative (categorical) data was performed in the form of number of cases and percent. Error bars represent 95\% confidence interval. ANOVA test and chi-square tests were used for comparison among different times in the same group in quantitative data. The significance level was set at P-value of 0.05 or less, and Pvalue of 0.01 or less was considered highly significant.

\section{RESULTS}

The demographic data showed no statistically significant differences in patient characteristics as regards age, sex, American Society of Anesthesiologists physical status, and duration of surgery.

There was no statically significant difference between groups as regards patient and surgery satisfaction. Also, there was no change in the sedation level after the peribulbar block and during the whole surgery in any of the three groups in comparison with the pre-block state. However, Regarding the need for supplementary injection there was statistical significance between the M \& D group when compared to the $\mathrm{C}$ group (Table 1). 
Table 1. Demographic data, duration of surgery, patient and surgery satisfaction, and sedation score.

\begin{tabular}{|c|c|c|c|c|c|}
\hline Parameters & $\begin{array}{c}\text { Group C } \\
\mathbf{N}=\mathbf{3 0}\end{array}$ & $\begin{array}{c}\text { Group M } \\
\mathbf{N}=\mathbf{3 0}\end{array}$ & $\begin{array}{c}\text { Group D } \\
\mathbf{N}=\mathbf{3 0}\end{array}$ & $\mathbf{f} / \mathbf{X}^{2}$ & $\mathbf{P}^{\text {-value }}$ \\
\hline Age (years) & $5.45 \pm 46.27$ & $6.39 \pm 43.35$ & $5.24 \pm 45.81$ & 2.264 & 0.110 \\
\hline Sex (male/ female) & $12 / 18$ & $16 / 14$ & $19 / 11$ & 3.295 & 0.192 \\
\hline ASA (I:II:III) & $3 / 23 / 4$ & $10 / 19 / 7$ & $5 / 22 / 3$ & 5.599 & 0.231 \\
\hline Duration of Surgery (min) & $7.56 \pm 117.7$ & $7.41 \pm 118.09$ & $8.25 \pm 115.33$ & 1.115 & 0.333 \\
\hline $\begin{array}{c}\text { Surgery satisfaction } \\
\text { Satisfied/unsatisfied }\end{array}$ & $2 / 28$ & $1 / 29$ & $4 / 26$ & 2.169 & 0.338 \\
\hline $\begin{array}{c}\text { Patient satisfaction } \\
\text { Satisfied/unsatisfied }\end{array}$ & $1 / 29$ & $1 / 29$ & $1 / 29$ & 0.000 & 1.000 \\
\hline No. of patient with RAMSY sedation score more than 3 & 0 & 0 & 0 & 0.000 & 1.000 \\
\hline $\begin{array}{c}\text { Patient needed supplementary injection } \\
\text { Yes/ No }\end{array}$ & $6 / 24$ & $0 / 30$ & $1 / 29$ & 9.604 & $0.008^{*}$ \\
\hline
\end{tabular}

$* \mathrm{P}<0.05$ is considered significant, $* \mathrm{P}<0.001$ is considered highly significant.

\subsection{Regarding the Block Characteristics}

The onset of globe anesthesia and the onset of globe akinesia were shorter in magnesium group in comparison with control group and dexmedetomidine group. The difference was highly statistically significant $(\mathrm{p}<0.001)($ Table 2$)$.

There was no significant difference in VRS score during surgery between the three groups. However, both the duration of globe akinesia\& analgesia were prolonged significantly in group D when compared to the other two groups with $\mathrm{P}$ value $<0.001$.

Table 2. The block characteristics.

\begin{tabular}{|c|c|c|c|c|c|c|c|c|}
\hline \multirow[t]{2}{*}{ Parameters } & \multirow{2}{*}{\multicolumn{2}{|c|}{$\begin{array}{c}\text { Group c } \\
\mathbf{N}=\mathbf{3 0} \\
\text { Mean } \pm \text { SD }\end{array}$}} & \multirow{2}{*}{\multicolumn{2}{|c|}{$\begin{array}{c}\begin{array}{c}\text { Group M } \\
\mathbf{N}=\mathbf{3 0}\end{array} \\
\text { Mean } \pm \text { SD } \\
\end{array}$}} & \multirow{2}{*}{\multicolumn{2}{|c|}{$\begin{array}{c}\text { Group D } \\
\mathbf{N}=\mathbf{3 0} \\
\text { Mean } \pm \text { SD } \\
\end{array}$}} & \multicolumn{2}{|c|}{ ANOVA } \\
\hline & & & & & & & P-value & f \\
\hline Onset of corneal anesthesia (min) & 0.74 & 2.32 & 0.53 & 1.45 & 0.92 & 1.78 & $<0.001 * *$ & 10.365 \\
\hline Onset of total globe akinesia ( $\mathrm{min}$ ) & 2.19 & 10.15 & 1.95 & 6.47 & 2.47 & 8.32 & $<0.001 * *$ & 20.729 \\
\hline Recovery of globe akinesia (min) & 21.87 & 161.74 & 26.18 & 182.61 & 28.43 & 208.06 & $<0.001 * *$ & 24.560 \\
\hline Duration of post-operative analgesia $(\mathrm{VRS} \geq 2) \mathrm{min}$ & 23.08 & 183.25 & 24.16 & 225.33 & 22.77 & 259.47 & $<0.001 * *$ & 80.243 \\
\hline
\end{tabular}

\subsection{Effect on Intra-ocular Pressure (IOP) in mmHg}

Within the same group a statistically significant decrease in the IOP was detected when comparing IOP 5 min and 10 min in Group D and group M to the baseline measurement ( $p$ value $<0.05$ ), while no significant differences were detected when comparing the IOP $5 \mathrm{~min}$ and $10 \mathrm{~min}$ to the baseline measurement in group C. Also, a statistically significant decrease was detected when comparing IOP $5 \mathrm{~min}$ and $10 \mathrm{~min}$ in Group D and group M to the same readings in the Group C, while no significance was found comparing the same measurements in both group (D, M) (Table 3).

Table 3. Effect on IOP in mmHg.

\begin{tabular}{|c|c|c|c|c|c|c|c|c|}
\hline \multirow{2}{*}{ Parameters } & \multirow{2}{*}{\multicolumn{2}{|c|}{$\begin{array}{c}\text { Group C } \\
\mathbf{N}=\mathbf{3 0} \\
\text { Mean } \pm \text { SD }\end{array}$}} & \multirow{2}{*}{\multicolumn{2}{|c|}{$\begin{array}{c}\text { Group M } \\
\mathbf{N}=\mathbf{3 0} \\
\text { Mean } \pm \text { SD }\end{array}$}} & \multirow{2}{*}{\multicolumn{2}{|c|}{$\begin{array}{c}\text { Group D } \\
\mathbf{N}=\mathbf{3 0} \\
\text { Mean } \pm \text { SD }\end{array}$}} & \multicolumn{2}{|c|}{ ANOVA } \\
\hline & & & & & & & P-value & f \\
\hline IOP Baseline (mmHg) & $3.45 \pm$ & 14.82 & $2.87 \pm$ & 15.07 & $3.21 \pm$ & 14.92 & 0.954 & 0.047 \\
\hline $\begin{array}{l}\text { IOP } 5 \text { min after injection } \\
(\mathrm{mmHg})\end{array}$ & $2.67 \pm$ & 14.57 & $3.26 \pm$ & 12.52 & $2.08 \pm$ & 12.38 & $0.003 *$ & 6.126 \\
\hline IOP $10 \mathrm{~min}$ after injection $(\mathrm{mmHg})$ & $2.42 \pm$ & 13.85 & $2.19 \pm$ & 11.23 & $3.46 \pm$ & 11.49 & $<0.001 * *$ & 6.283 \\
\hline
\end{tabular}

$* \mathrm{P}<0.05$ is considered significant, $* \mathrm{P}<0.001$ is considered highly significant.

\section{DISCUSSION}

Peribulbar block is commonly used for vitreoretinal surgery in adult but using traditional mix of local anesthetic drugs (bupivacaine $0.5 \%$ + lidocaine $2 \%$ ) for peribulbar anesthesia is usually associated with delayed onset of globe akinesia and corneal anesthesia, short duration of analgesia and frequent need of block supplementation, to overcome this obstacle many adjutants were added to local anesthesia. In our study, we planned to compare between 
dexmedetomidine and Magnesium sulphate as an adjuvant to local anesthetic mixture using the single injection technique for percutaneous peribulbar anesthesia with a short needle as described by Rizzo et al. [11] it has been proved to be a simple and easy-to-perform technique with less pain, using a decreased volume of local anesthetic. The hypothesis of the efficacy of this technique was revealed in previous studies [12] using B-scan ultrasonography which demonstrated that a small volume of local anesthetics diffused circumferentially from the extraconal to the intraconal space, where the sensory and motor nerves of the eye are located [13].

In the study, ninety patients were allocated in three equal groups (30 each), group C (control group), group $\mathrm{M}$ (50 mg magnesium sulphate added to the LA mixture), and group D (50 $\mu \mathrm{g}$ of dexmedetomidine added to the LA mixture).

The Magnesium group (group M) showed rapid onset to establish the block than the dexmedetomidine and control groups leading to less delay in surgery and more suitable conditions to operate in less than 10 mins. El-Hamid [14] proved that magnesium had a significant rapid onset of globe and lid akinesia when compared with clonidine as an adjuvant to local anesthetic in peribulbar block for posterior segment eye surgeries. Also, Narang et al. [15] observed that the addition of magnesium sulfate as adjunct to lignocaine for total intravenous anesthesia for upper limb surgery enhanced the onset of sensory and motor block and decreased tourniquet pain.

In contrast, Lee et al. [16] observed no difference in onset times and duration of sensory and motor blocks in magnesium sulfate group and normal saline group with $0.5 \%$ bupivacaine with epinephrine in interscalene nerve block for arthroscopic rotator cuff repair. They only found statistically significant prolongation of analgesia in the magnesium group than in the saline group. Also, Tamer and Bestarous [17] compared the use of Magnesium sulfate with that of Rocuronium as an adjuvant to the local anesthetic in peribulbar anesthesia for cataract surgery, they reported that the addition of magnesium sulfate did not show any benefit as regards the onset of the block.

Whereas in another study by Hala and Ayman [18], who studied the effect of adding two different doses of dexmedetomidine $(25 \mu \mathrm{g}$ and $50 \mu \mathrm{g})$ to Levo-bupivacaine/hyaluronidase mixture and assessed their effects on the onset and duration of globe anesthesia and akinesia, they found out that both doses significantly enhanced the onset of corneal anesthesia and globe akinesia than in the control group but the $25 \mu \mathrm{g}$ group had better hemodynamic stability.

In our study, the dexmedetomidine group showed prolonged duration of the block reflected as prolonged postoperative analgesia rather than $\mathrm{M}$ group or $\mathrm{C}$ group. This goes with Channabasappa et al. [19] who found out that patients who received $25 \mu \mathrm{g}$ dexmedetomidine added to their anesthetic mixture used in the peribulbar block, showed a statistically significant increase in the duration of akinesia compared to the group of patients who received only the local anesthetic mixture. Also, in Reem and Khashaba [20] study, the duration of globe analgesia and globe akinesia showed a statistically significant increase in both groups of study (the clonidine group and dexmedetomidine group) in comparison with the control group. But this advantage doesn't have a statistical impact on patient or surgery satisfaction.

Regarding the IOP, the addition of magnesium or dexmedetomidine to the local anesthetic mixture in group $\mathrm{M}$ and group D showed a statistically significant decrease in the IOP $5 \mathrm{~min}$ and $10 \mathrm{~min}$ after the injection of the local anesthetic mixture when compared to the baseline measurement of the same groups and the control group. While no significant differences were detected when comparing the IOP $5 \mathrm{~min}$ and $10 \mathrm{~min}$ in both $\mathrm{M}$ and $\mathrm{D}$ groups. These results were correlating with those of Hafez et al. [9] and El-Raouf et al. [10], where they found that the addition of magnesium and dexmedetomidine to LA mixture caused a statistically significant decrease in IOP compared to control group at 1,5 , and $10 \mathrm{~min}$.

There were no adverse effects or complications related to the technique and the drugs used, the patients were hemodynamically stable throughout the procedure this could be attributed to small doses of the drug used also there was no difference between the groups regarding the patient's sedation level, furthermore both surgeon and patients satisfaction were almost the same between the three groups. However, regarding the need of supplementary injection there was statistical significance between the $M \& D$ group when compared to the $C$ group but there was no statistical significance between the M \& D groups which further justify their effectiveness as adjuvants in extending the sensory and the motor block duration.

Although, the number of patients and using single type of ophthalmic surgery with fixed concentrations could be a limitation to our study, however, the significant decrease in IOP caused by magnesium and dexmedetomidine should be further investigated, this advantage opens research gate to be useful in glaucoma surgery. 


\section{CONCLUSION}

Adding $50 \mathrm{mg}$ Magnesium sulphate to a mixture of lidocaine 2\% and bupivacaine in peribulbar block shortened sensory and motor block onset, and extended the analgesia period and the motor block duration. It also significantly decreased the intraocular pressure and enabled better operation conditions. It is comparable and safe as adding dexmedetomidine but better as cost-effectiveness and availability rather than dexmedetomidine in our country.

\section{ETHICS APPROVAL AND CONSENT TO PARTICIPATE}

Local Ethical Committee (Ain Shams Hospital) approval have been obtained before patient's allocation.

\section{HUMAN AND ANIMAL RIGHTS}

No Animals were used for studies of this research. All clinical investigations were conducted according to the Declaration of Helsinki (https://www.wma.net/policies-post/wma-declaration-of-helsinki-ethical-principles-for-medical -research-involving-human-subjects/) principles.

\section{CONSENT FOR PUBLICATION}

informed written consents were obtained from the allocated patients.

\section{CONFLICT OF INTEREST}

The author declares no conflict of interest, financial or otherwise.

\section{ACKNOWLEDGEMENTS}

Declared none.

\section{REFERENCES}

[1] Mein CE, Woodcock MG. Local anesthesia for vitreoretinal surgery. Retina 1990; 10(1): 47-9. [http://dx.doi.org/10.1097/00006982-199010010-00008] [PMID: 2343191]

[2] Bharti N, Madan R, Kaul HL, Khokhar SK, Mishra S. Effect of addition of clonidine to local anaesthetic mixture for peribulbar block. Anaesth Intensive Care 2002; 30(4): 438-41. [PMID: 12180581]

[3] Roberts JE, MacLeod BA, Hollands RH. Improved peribulbar anaesthesia with alkalinization and hyaluronidase. Can J Anaesth 1993; 40(9): 835-8. [http://dx.doi.org/10.1007/BF03009254] [PMID: 8403178]

[4] Reah G, Bodenham AR, Braithwaite P, Esmond J, Menage MJ. Peribulbar anaesthesia using a mixture of local anaesthetic and vecuronium. Anaesthesia 1998; 53(6): 551-4. [http://dx.doi.org/10.1046/j.1365-2044.1998.00433.x] [PMID: 9709140]

[5] Küçükyavuz Z, Arici MK. Effects of atracurium added to local anesthetics on akinesia in peribulbar block. Reg Anesth Pain Med 2002; 27(5): 487-90. [http://dx.doi.org/10.1097/00115550-200209000-00008] [PMID: 12373696]

[6] Aissaoui Y, Belyamani L, Kamili ND. Effect of the addition of rocuronium to local anesthetics for peribulbar block. Acta Anaesthesiol Belg 2010; 61(2): 51-4. [PMID: 21155437]

[7] Do SH. Magnesium: A versatile drug for anesthesiologists. Korean J Anesthesiol 2013; 65(1): 4-8. [http://dx.doi.org/10.4097/kjae.2013.65.1.4] [PMID: 23904932]

[8] Weijtens O, Schoemaker RC, Lentjes EG, Romijn FP, Cohen AF, van Meurs JC. Dexamethasone concentration in the subretinal fluid after a subconjunctival injection, a peribulbar injection, or an oral dose. Ophthalmology 2000; 107(10): 1932-8. [http://dx.doi.org/10.1016/S0161-6420(00)00344-4] [PMID: 11013202]

[9] Hafez M, Fahim MR, Mona HEA, Maha MIY, Salem AS. The effect of adding dexmedetomidine to local anesthetic mixture for peribulbar block in vitreoretinal surgeries. Egypt J Anaesth 2016; 32: 573-9. [http://dx.doi.org/10.1016/j.egja.2016.07.005]

[10] Mohamed A, El-Rouf, Osman M. Hefzy, Ahmed A. Badwy, Mohamed A-Aziz, Norhan A. Sherif. Evaluation of the effect of using magnesium sulphate as an adjuvant to regional anesthesia for ophthalmic surgery using peribulbar block med. J Cairo Univ 2016; 84: 283-8.

[11] Rizzo L, Marini M, Rosati C, et al. Peribulbar anesthesia: A percutaneous single injection technique with a small volume of anesthetic. Anesth Analg 2005; 100(1): 94-6. [http://dx.doi.org/10.1213/01.ANE.0000140951.65240.94] [PMID: 15616059] 
[12] Ghali AM, Mahfouz A, Hafez A. Single-injection percutaneous peribulbar anesthesia with a short needle versus sub-Tenon's anesthesia for cataract extraction. Saudi J Anaesth 2011; 5(2): 138-41. [http://dx.doi.org/10.4103/1658-354X.82780] [PMID: 21804792]

[13] Ripart J, Lefrant JY, Prat-Pradal D, Vivien B, Eledjam JJ, Eledjam JJ. Peribulbar versus retrobulbar anesthesia for ophthalmic surgery: An anatomical comparison of extraconal and intraconal injections. Anesthesiology 2001; 94(1): 56-62. [http://dx.doi.org/10.1097/00000542-200101000-00013] [PMID: 11135722]

[14] El-Hamid AM. Evaluation of the effect of magnesium sulphate vs. clonidine as adjuvant to local anesthetic during peribulbar block. Ain Shams J Anesthesiol 2011; 4: 21.

[15] Narang S, Dali JS, Agarwal M, Garg R. Evaluation of the efficacy of magnesium sulphate as an adjuvant to lignocaine for intravenous regional anaesthesia for upper limb surgery. Anaesth Intensive Care 2008; 36(6): 840-4. [PMID: 19115654]

[16] Lee AR, Yi HW, Chung IS, et al. Magnesium added to bupivacaine prolongs the duration of analgesia after interscalene nerve block. Can J Anaesth 2012; 59(1): 21-7.

[http://dx.doi.org/10.1007/s12630-011-9604-5] [PMID: 22012543]

[17] Tamer Y. Hamawy and John N. Bestarous rocuronium versus magnesium as an adjuvant to local anesthetics in peribulbar block. Ain Shams J Anesthesiol 2013; 6: 317-21.

[18] El-Ozairy Hala S, Tharwat Ayman I. Comparative study of the effect of adding two different doses of dexmedetomidine to levobupivacaine/hyaluronidase mixture on the peribulbar block in vitreoretinal surgery. Ain-Shams J Anesthesiol 2014; 7: 393-9. [http://dx.doi.org/10.4103/1687-7934.139576]

[19] Channabasappa SM, Shetty VR, Dharmappa SK, Sarma J. Efficacy and safety of dexmedetomidine as an additive to local anesthetics in peribulbar block for cataract surgery. Anesth Essays Res 2013; 7(1): 39-43. [http://dx.doi.org/10.4103/0259-1162.113987] [PMID: 25885718]

[20] El Kabarity Reem H, Khashaba Mohamed Y. Dexmedetomidine versus clonidine as an adjuvant to peribulbar block in vitreoretinal surgery. Ain-Shams J Anesthesiol 2012; 5: 288-94.

\section{(C) 2018 Aktham Shoukry.}

This is an open access article distributed under the terms of the Creative Commons Attribution 4.0 International Public License (CC-BY 4.0), a copy of which is available at: (https://creativecommons.org/licenses/by/4.0/legalcode). This license permits unrestricted use, distribution, and reproduction in any medium, provided the original author and source are credited. 